\title{
Response to Stephen Davis
}

\section{Christopher Ives}

Traditionally, Mahayana Buddhism has made the claim that our ordinary cognitive process, the 'mind' that produces the concepts and theories found in conventional knowledge, fails to grasp reality. Moreover, that process gives rise to the notion of independent 'things' and to attachment - attraction and aversion - to those reified things, which causes suffering. For these interconnected epistemological and soteriological reasons, the normal thinking 'mind' must be thoroughly negated. Upon this negation, one awakens to liberated knowledge (paramārtha-satya) or wisdom (prajñā), in which one experiences reality without the distortion caused by ordinary conceptualization. Describing reality experienced through wisdom, Mahayana Buddhists may state that 'nothing in the world has any self-existence' or that 'reality is dependent co-origination', all the while recognizing the inability of words to convey their experience adequately. On the basis of the conviction that wisdom does grasp the nature of reality but ordinary cognition and concepts do not, Zen Buddhism ultimately appeals to practice and Awakening. As Tê-shan (780-865) declared before burning his notes and commentaries on the Diamond Sutra, 'Even though one masters various profound philosophies, it is like placing a single strand of hair in the great sky; even if one gains all the essential knowledge in the world, it is like throwing a drop of water into a deep ravine' (Zenkei Shibayama, Zen Comments on the Mumonkan, New York: Harper \& Row, 1974, p. 201). 